\title{
Unfair Payment Issues in Construction: Re-Thinking Alternative Payment Method For Tier-1 Contractors to Subcontractors
}

\author{
Laura Peter Swai \\ lauralps006@yahoo.com \\ School of Energy, Construction and Environment, Coventry University, Coventry, UK \\ Andrew Oyen Arewa \\ andrew.arewa@coventry.ac.uk \\ School of Energy, Construction and Environment, Coventry University, Coventry, UK \\ Rex Asibuodu Ugulu \\ rexugulu@gmail.com \\ School of Environmental Technology / Quantity Surveying Dept., Federal University of Science and \\ Technology (FUTO), Nigeria
}

\begin{abstract}
Recent statistics reveal substantial increase in late payments cases from $18 \%$ to $27 \%$; with over $£ 30$ billion unpaid invoices to UK contractors. Furthermore, $82 \%$ of overdue invoices are monies owed to subcontractor by tier-1 main contractors. Indeed, tier-1 contractors are deemed to be the main elephant in the room despite various contractual, government and private initiatives designed to curb late payment menace. Yet, there is little research concerning use of Alternative Payment Method (APM) to leverage tier-1 contractors paying subcontractors' invoices promptly. The aim of this study is to assess the use APM to enhance pragmatic and sustainable payment practices between tier-1 contractors and subbies. The research question is: what are the industry specific factors that influences unfair payment practices and how can alternative payment method help to leverage fair payments to subbies? The study adopted sequential exploratory design type of mixed method supported by questionnaire and structured interviews. The study population are drawn from experienced industry stakeholders including clients, contractors, designers, professionals in addition to use of computer simulation to validate proposed APM model. Initial findings reveal an optimism bias tendency of most subcontractors agreeing to lengthened and unfair payments terms induced by Tier 1 contractors. The study identified over five industry and business specific influential factors that encourages tier- 1 contractors to clinch to unpropitious late payment practices. In specific terms, there are overwhelming evidences that APM has significant potential to minimize late payment in the UK construction industry if there is political, business and legislative will to implement the model.
\end{abstract}

Keywords: Alternative payment methods; Construction industry; Unfair payment

\section{INTRODUCTION}

Globally, unfair payment practices such as late payment to contractors, "pay when paid", disparaging rate of items, exclusion of provisional items, imposition of rates and unpaid retentions remains a reoccurring problem in the construction industry. In the UK, subcontractors that carryout works for Tier 1 contractors are disproportionately affected by unfair payment practices. The Federation of Small Business (FSB, 2017) 
claims that "in the last five years, two-third of subcontractors in UK construction industry experienced longer payments period of over six weeks". The Euler (2015) report assert that there has been substantial increase in unfair payment cases from $18 \%$ to $27 \%$; with over $£ 30$ billion unpaid invoices and $£ 7$ billion of unremitted retention monies over the past five years. Moreover, $82 \%$ of total unpaid invoices are monies owed to subcontractors by Tier- 1 contractors. Recent statistics reveal that on average it takes 65 days approximately for tier 1 main contractor to pay subcontractor from the day of receiving invoices (Build UK, 2018). Also "Lost in Transaction: Payment Trends report" (2018) and "Construction Payments Report" (2018) both emphasized the need for genuine review of complex and unfair payment practices in the construction industry. Specifically, Construction Payment report (2018) claimed that the industry is in dire need of Alternative Payment Method (APM) that will synchronize and deliver fair payments to construction supply chain. Yet, there is little research that clearly identifies business and industry specific factors that influences unfair payment practices, and the use of APM to enhance prompt payment of invoices by tier-1 contractors to subbies.

Review of current payment model in the construction sector show a bias design that focuses on boosting Tier 1 contractors' cash flow at the expense of their supply chain. Generically, contractual payments procedures allow for weekly or monthly remittance of money to supply chain; but distribution of payments to subcontractors especially from Tier 1 contractors are often lopsided. The cascade payment method in construction also known as hierarchical contractual framework gives Tier 1 contractor dominant bargaining position over subcontractors' payment. Yet, it is a common practice to see subcontractors that carryout over $74 \%$ of major work, wait for 60 days to receive payments (FSB, 2017), due to commercial influence of Tier 1 contractors and archaic payment methods.

\section{RELATED LITERATURE}

\section{Unfair payment practice in Construction Industry}

Unfair payment practices are still common down supply chain in the UK construction industry; despite various regulations such as the Housing Grants Construction and Regeneration Act (HGCRA, 1996), (Late Payment of Commercial Debts Regulation, 2013), and other private initiatives. Recent statistics indicate significant deterioration of payments from Tier 1 contractors to subcontractors, with average payment period of 65 days and in worst scenario 120 days (Build UK, 2018).

Kilgallon (2013) opine that unfair payment practices give rise to additional financing, transactional costs, erode credit rating of affected companies, breed mistrust and adversarialism in supply chain. As a result, clients will experience more expensive projects, with devastating knock-on effect on contractors' cash flow. Latham (1994) stress that unfair payment practices cause significant waste and inhibit productivity through mistrust and confrontation, which ultimately undermines project performance. Uncertainty over how much and when payments are to be made often-lead to big distraction to subcontractors and suppliers that operates with low capital outlays and thin margins.

Build UK (2018) assert that unfair payment practices (especially late payment) contribute significantly to high rate of insolvency; "on average one in ten firms go burst daily in the UK construction industry". Indeed, late payment creates cash flow problems 
exacerbated by tough economic climate and banks reluctance to lend in money. Arguably, the demise of Carillion Plc 2017/18 and current Kier financial warnings are concreated to payment issues. Today, late payment to supply chain has become a common characteristic of construction companies that are struggling financially.

\section{Key Definitions}

The phrase "unfair payment practice" used in the study is drawn from the UK Department for Business, Innovation and Skills (2017) report titled "Challenging Grossly Unfair Payment Terms and Practices". The report defines "unfair payment" based on Late Payment Act 1998 provision, Section 4 subsection (7A) under three specific aspects as: (i) anything that is a gross deviation from good commercial practice and contrary to good faith and fair dealing; (iii) the nature of the goods or services in question; and (iii) whether the purchaser has any objective reason to deviate from the stipulated/contractual payment term.

The report subsequently identified unfair payment practices as: late payment to contractors/suppliers, "pay when paid", disparaging rate of items, exclusion of provisional remedy, imposition of rates on subcontractors and unpaid retention to contractors as common grossly unfair commercial practices in the UK construction industry. FSB (2017) argued that globally late payment to contractor is the most common unfair payment practices in construction. Ameer (2005) define late payment as failure of paymaster to issue or honor payments as stated in contractual agreement. Zurich index (2017) opine that over half of small and medium sized businesses spend on average $£ 16,000$ per year chasing late-payment. Recent survey conducted by BEIS (2018) reveals that $33 \%$ of subcontractors had experienced business difficulties as result of late payments.

Ramachandra and Rotimi (2015) suggest that issues of late payments with subcontractor are multifaceted. Abdul Rahman et al. (2010) argued that contractors' poor finance management, disagreement in valuation of work done, use of "pay-when -paid" tactics and insufficient documentation are major causes of late-payments to contractors. Rotimi et al. (2010) claim that the industry payment culture of "work first and then get paid later" is responsible for deferred payment attitude particularly by Tier 1 main contractor. Other authors such Ramachandra (2013) and Danuri et al. (2006) argued that existence of low entry barriers, inadequate capital and the use of "cow boy bullying" tactics by Tier 1 contractors all contributes to chronic unfair payment issues in the industry. Arewa and Farrell (2016) suggest that commercial interest of many Tier 1 contractors' influences unfair payment practices in the construction sector. Indeed, existence of multi-tiered hierarchical structure together with cascade payment obligation places most subcontractors and suppliers at risk of unfair payments practices in the construction sector (Griffiths et al., 2017).

\section{Existing Payment Methods from Tier-1 Contractors to Subcontractors}

The Egan (1998) report titled "Rethinking Construction" asserted that current payment methods in construction places a considerable and unfair strain between parties, which in turn affects overall spirit of team working, partnering and supply chain management. Moreover, there is an overwhelming consensus that current payment methods are designed to consider individual project characteristics and cash flows models that favor 
Tier 1 contractors compared to subcontractors and suppliers. For example, the use of cost reimbursement payment method to provide compensation for work done by contractors for using their own resources and expertise in terms of buildability, cost of materials and programme, only to be reimburse at a later date is grossly unfair (Master, 2002). Arditi and Yasamis (1998) are of the view that current interim valuation and payment methods in construction industry can best be described as "incentive that compels contractors to perform". Pye-Tait (2016) argue that financial protection methods such as bonds, parent company guarantee, escrow accounts and trust funds are becoming obsolete. However, useful in protecting clients against contractor's insolvency and nonperformance, some of these financial instruments usually creates untold financial burden on subcontractors. Moreover, significant of trade credit payment method (pay later after delivery of construction works/materials) cannot be overemphasized, particularly from main contractors' perspective. However, it is important to stress that most Tier 1 contractors see trade credit as a vital business model in sustaining their working capital and profit margins at the detriment of their subcontractors and suppliers.

In the last decade, the use of project bank accounts (PBA) in public projects as a form of payment method is considered a panacea to chronic unfair payment practices in the construction sector. Indeed, PBA provides effective means of addressing waste issue and achieving fair payment through transparency and auditability of its supply chain payments (Kilgallon, 2013). PBA acts as ring fenced electronic bank account in which timely payments are made directly and simultaneously to main contractors and its supply chain. The payment model ensure that clients maintain adequate funds that will cover work in progress and other project commitments. Under a PBA, the subcontractors submit interim application to main contractor showing breakdown of payments claimed by each supplier with the purpose of counterchecking if necessary adjustment are required. Once approved, the client will pay total amount of monies into PBA and direct payments will be made to each subcontractors and suppliers in the supply chain. If the clients want to reduce or adjust payments due to contractor's defaults, the contractor will be required to make a top-up payment into account so that subcontractors and suppliers can be paid on time. To avoid deficit of payments under PBA arrangement, client must ensure that the balance remains at an agreed minimum level (Kilgallon, 2013).

Arguably, the novelty behind aforementioned PBA payment model is that it has been proven to be effective; unlike other payment methods where Tier 1 contractor deliberately withhold payment from subcontractors to boost their working capital and profit margins. In the UK, most payment methods still reflect 19th century business model that enable Tier 1 main contractor to dictate payment terms and disbursement to supply chain. The cascade payment method is for main contractor to receive monthly payments for completed works on site and then distribute those payments to subcontractors and suppliers in the chain. Payment method based on such hierarchical contracting approach per se limits the margin of negotiation between client and subcontractors' thereby putting unnecessary strain between parties.

Danuri et al. (2006) argued that Tier 1 contractors often exert considerable commercial pressure on subcontractors to agree longer payment terms in order to boost their cash flow. For example, many Tier 1 contractor such as Carillion Plc, Interserve and Kier Plc use late payments as a tool for financing their business performance. On the contrary, 
most subcontractors are often reluctance to challenge current unfair payment practices, because of clients-contractor relationships and fear of being dropout from the supply chain.

\section{RESEARCH METHOD}

The research design adopted sequential explanatory type of mixed methods with QUAN $\rightarrow$ QUAL concept meaning quantitative method is the lead data collection instrument (Creswell, 2015). While, qualitative data are used to support and validate the quantitative findings. The data collection tools for the study includes semi-structured interview and questionnaires. The study questionnaire and interview questions were designed based on existing literature. Pilot studies were conducted to ensure that the data collection tools were designed correctly. Ethnical approval was sought from Coventry University Research Ethics Committee and it was granted, see attached ethics certificate in appendix A. Data collected for the study were obtained from difference location in England and Scotland. The main data collection instruments were designed to answer the study research questions. Stratified random sampling was used to select the study participants for both quantitative and qualitative data. A semi-structured questionnaire was distributed through emails, telephone contact, site visits and through The Chartered Institute of Building (CIOB) and Royal Institution of Chartered Surveyors (RICS) professional networking. All interviews were conducted face-to-face to obtain first-hand information about the research problem.

The population sample consist of, construction clients, commercial managers, contract managers, commercial lawyer, quantity surveyors, managing directors of construction firms and business development manager. For reliability and validity, the study data collection (both questionnaire and interview data) were conducted on one-toone basis. This method allowed the researchers to probe participants regarding the study aim and research question. On the other hand, the study participants had opportunity to ask questions that were not clear.

\section{Quantitative Data Analysis}

Total of 96 questionnaires were administered, 89 were returned and six were considered invalid because they were not completed correctly. Total of 83 questionnaires were used for statistical analysis; performed using SPSS version 25. Cronbach's alpha sigma value of 0.81 was obtained meaning that internal reliability of the quantitative data is very good. Exploratory Factor Analysis (EFA) was used to determine underlying relationship between combinations of factors that influences unfair payment practices in the construction industry. The factor loading was run for both Principal Axis (PA) and Principal Component Analysis (PCA). The communality factor was calculated to be $\mathrm{C} 2$ $=0.5842+0.4952=0.765$. Therefore, because the communality factor is close to 1 ; it indicates that unfair payment variables measured by the study were better explained by the factors. Table 1 illustrates percentage commonality of unfair payment practices claims by construction contractors in the UK construction industry. The greatest percentage score (late payment to contractors) scored $34 \%(\mathrm{n}=83 \%)$ was attributed to industry and business factors presented in Table 1 below. 
Table 1: Percentage of commonality of unfair payment practices claims by construction contractors

\begin{tabular}{|l|c|c|}
\hline \multicolumn{3}{|c|}{ Percentage commonality of unfair Payment Practices } \\
\hline Variables of unfair payment practices test & $\mathbf{n}$ & $\mathbf{\%}$ \\
\hline Late payment to contractors & 28 & 34 \\
\hline "Pay when paid" & 3 & 3 \\
\hline Disparagingly rate of items & 8 & 10 \\
\hline Exclusion of provisional remedy & 15 & 18 \\
\hline Imposition of rates on contractors & 10 & 12 \\
\hline Unpaid retention to contractors & 19 & 23 \\
\hline Total & $\mathbf{8 3}$ & $\mathbf{1 0 0}$ \\
\hline
\end{tabular}

For better understanding of the research problem, construction clients were classified as following: Tier 1 client: major construction clients e.g. government authorities and private institutions; Tier 2 clients: main contractors acting as client to subcontractors) and Tier 3 clients: subcontractors acting as clients to other subcontractors. Using Relative Importance Index (RII) and Quadrant analysis, 42 cases of contractors complains about factors and extent of unfair payment practices were analyzed alongside classification of different clients. Figure 1 illustrate tiers of construction clients with awful unfair payment practices in the UK construction industry. Figure 2 summarizes industry and business specific factors that influences unfair payment practices in the UK construction industry.

\section{Magnitude of unfair payment practices on construction clients}

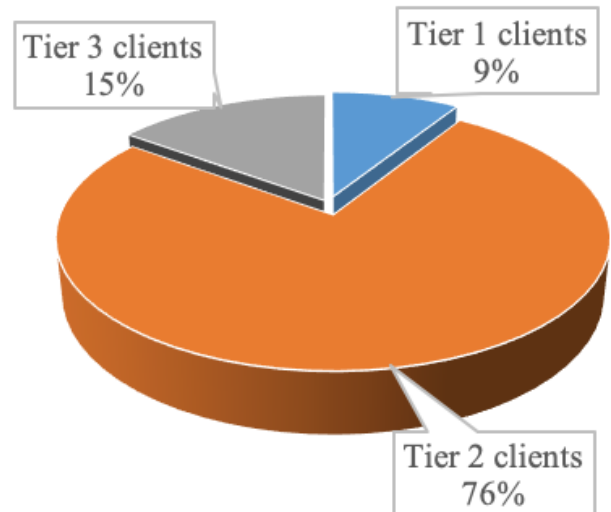

Figure 1: Magnitude of Unfair payment practices on Construction clients

Total of 83 subcontractors that regularly work for main contractors were asked to identify industry and business specific influential factors that encourage Tier 2 clients (principal contractors) to indulge in unfair payment practices without punitive measures. Figure 2 presents key percentages of influential factors that encourages Tier 2 clients to coddle unfair payment practice in the UK construction industry. 


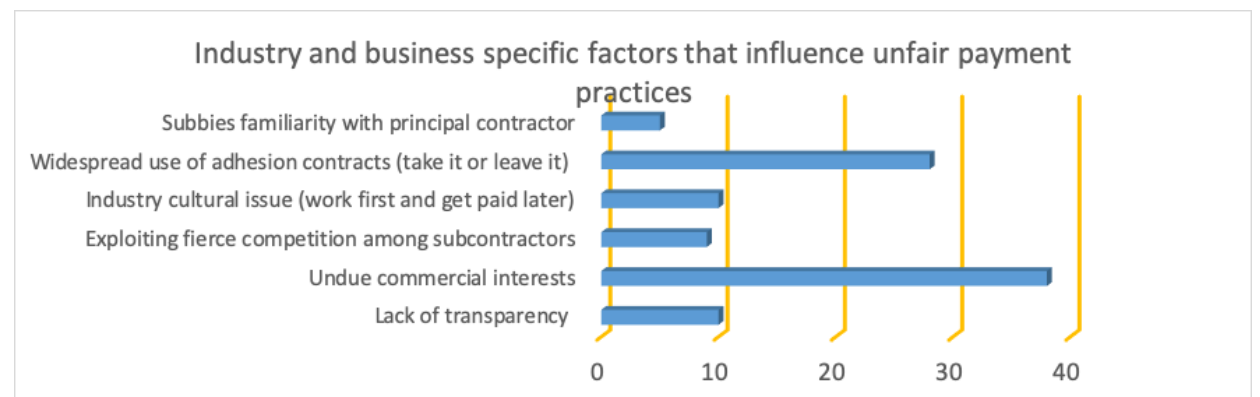

Figure 2: Industry and business specific factors that influences unfair payment practices

\section{Interviews data analysis}

Validity of the study qualitative data was upheld in three main areas: selection of participant profile, design of interview questions, and processing/presentation of interview data. Overall, a total of 13 semi-structured interviews were conducted with clients, industry practitioners and construction contractors. The study targeted interviewees with seasoned construction experience. All interviews were recorded using a digital recorder and personal information linked to study participants was removed because of data protection.

Textual excerpts of the interview data were transcribed into manuscript and inputted into Nvivo 12 software. Codes were assigned to key themes to facilitate filtering and sorting of data. The themes from the study aim were used to create codes and sub-codes from the transcribed data. Content analysis was used to analyze the interview data for easy inferences to antecedents of discussions and certain words, themes or concepts spoken between interviewees and interviewer. Excerpts from interviews below were obtained using content analysis; by counting number of processes, extracting systematic and objective meaning from each content via making valid inferences from verbal and archive data. For example, when interviewees were asked to express their view concerning unfair payment practices in the UK construction industry; host of issues were raised about the subject matter. Subsequently, key contents were trimmed for better understanding and spontaneity of interaction between the researcher and study participants. Some textual excerpts are expressed verbatim; as illustrated below for confirmability and better understanding of participants' view points.

“... the culture of 'work first and get paid later' is undeniably the root causes of unfair payment practices ... these problems exist because clients need to be protected from the hands of dodgy contractors; but some clients are exploiting unfair payment for their personal gain" - (Public clients Head of Construction procurement Local Government authority UK)

“.... we have seen different kind of measures and methods implemented by government and private sectors to ensure prompt and timely payments ... but these efforts and procedures still give main contractors a room to wiggle when it comes to real enforcement of payment terms..." (Senior Project Finance Officer to main construction company) 
"... the current payment methods in the construction sector are indefensible and longterm pain to subcontractors and suppliers ...." (Director UK Department for Business, Energy and Industrial Strategy)

Interview data presented above suggest that current payment methods in the construction industry are indefensible, unsustainable and subject subcontractors and suppliers to significant financial stress. However, interviewees were asked to explicate how alternative payment methods can bring about feasible and sustainable payment practices particularly between tier-1 contractors and subcontractors.

"... in our previous projects we used project bank accounts to pay contractors and our supply chain which worked perfectly well ... though it had major contractual complications with pay less notice ... the principal contractors never liked it ... " (Senior Commercial Manager Railway infrastructure Project, UK)

“... I can confidently say that most payment methods and regulations have loopholes ... alternative payments method that ring fence payment to supply chain is perhaps the only sustainable solution to this mess" (commercial lawyer - London)

\section{FINDINGS AND DISCUSSION}

The study literature provided clear understanding of unfair payment practices in the construction industry. Findings from literature and data analysis have unanimous findings. For example, both literature and key findings from the study support the premise that unfair payment practices exist in the industry; and a major issue to both contractors and subcontractor's financial performance. Perhaps, the study literature was grossly limited in terms of scale, extent and industry specific factors that influences unfair payment practices in construction. The study quantitative and qualitative inquiries clearly identified six business and industry factors that influences unfair payment practices as illustrated in figure 1 . The study acknowledged that undue commercial interest of main contractors and widespread use of adhesion contracts (take-or-leave) or "back-to-back" types of contractual agreement between Tier 2 contractors and subcontractors as the foremost factors that influences unfair payment in the construction industry. Besides, the study specifically measured type of client's involvement to unfair payment issues. Quantitative findings reveal that $57 \%$ of unfair payment cases are akin to late payment $(34 \%)$ and retentions on subcontractors as illustrated in table 1. However, unfair payment issues certainly go beyond Tier 1 contractors' behavioral issues. Perhaps, subcontractors and other suppliers are complicit as well, because they often exhibit optimism bias tendency by agreeing to lengthened and unfair payments terms induced by them. Moreover, there was unified suggestions from qualitative inquiry that use of PBA (a ring fence payment to supply chain) is perhaps the only sustainable solution to chronic unfair payment problems in the construction industry. However, some study participants believe that there are loopholes to PBA. Thus, the study is proposing an enhance Alternative Payment Method (see figure 3) to enhance prompt payment of invoices from Tier-1 contractors to subcontractors. 


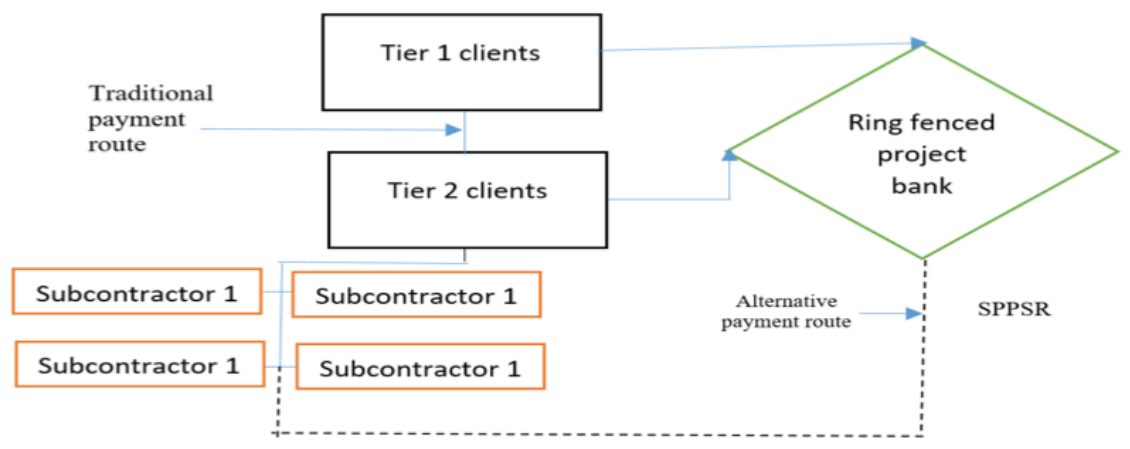

Figure 3: Proposed alternative payment method for construction contractors and suppliers

The main difference between PBA and proposed APM is the introduction of Special Purpose Payment System Regulator (SPPSR) to act as independent regulator. Besides, SPPSR is to act as trustee and guarantor for prompt fortnightly payments to contractors and suppliers. The mandate of the special purpose payment system is to minimize main contractor domineering power over subcontractors' monies and insolvency risks of subcontractors. However, the main contractor still needs to audit and certified interim valuation, before SPPSR releases monies to subcontractors. The proposed initiative is similar to the non-for-profit Tenancy Deposit Scheme (TDS) managed by National Housing Association and regulated by Housing Act 2004. There is need for the proposed APM to be backed by an Act of Parliament; for easy punitive measures against erring tier2 clients.

\section{CONCLUSION}

The aim of the study is to investigate specific factors that influences unfair payment practices in the UK construction industry. The study identified six business and industry specific influential factors that encourages unfair payment particularly from Tier 2 clients (main contractors) to subcontractors. The factors include: undue commercial interests from Tier 2 clients, lack of transparency, fierce competition among subcontractors, industry culture "work first and get paid later", and widespread use of adhesion contracts "take it or leave it" agreement, as illustrated in figure 2.. Moreover, the quantitative inquiry reveals that late payment $(34 \%)$ and imposition of rate on subcontractors $(23 \%)$ are the most common types of unfair payment practices in the construction industry. Findings also show that Tier 2 clients (main contractors) accounted for $86 \%$ of unfair payment cases, while $9 \%$ and $5 \%$ were linked to Tier 3 and Tier 1 clients respectively. Indeed, implication of these findings is that main contractors have and do exert strong commercial influence over their subcontractors and suppliers in the construction industry. Yet, factors that encourages unfair payment practices in the industry are hardly challenged by subcontractors. Ultimately, to minimize unfair payment issues and enhance prompt payment of invoices from tier-1 contractors to subcontractors the study proposed use of APM. The proposed payment method is significant because if its ring fenced, guarantor and legal features. The proposed payment method is still undergoing research development, modification, consultation and subsequent validation with stakeholders. 


\section{REFERENCES}

Abdul-Rahman, A., Munaaim, M. E. C., Danuri, M. S. M. \& Berawi, M. A. (2008). Issues affecting payments in the building and construction industry of a rapidly developing economy. Building Engineer Journal, 3-9.

Ameer Ali, N. A. N. (2005) Payment in The Construction industry - towards Zero Default. QS National Convention 2005, 10 -11August 2005, Hilton Kuala Lumpur.

Arditi, D. \& Yasamis, F. (1998) Incentive/disincentive contracts perceptions of owners and contractors. Journal of Construction Engineering and Management, 124(5) 361-71.

Clough, R. H. \& Sears, G. A. (1994). Construction contracting. 6ed. John Wiley and Sons Inc. New York Construction Payments Report (2018).

Danuri, M. S. M., Munaaim, M. E. C., Rahman, H. A. \& Hanid, M. (2006). Late and non-payment issues in the Malaysian Construction Industry - Contractor's perspective. In: International Conference on Construction, Culture, Innovation and Management (CCIM), 26-29 November, Dubai Department for Business, Energy \& Industrial Strategy (2017) report titled "Retention Payments in the Construction Industry a consultation on the practice of cash retention under construction contracts". Published by GOV.UK. October, pp. 3-5.

Egan, Sir J. (1998) Rethinking Construction. London: Department of the Environment, Transport and the Region.

Euler Hermes (2015). Euler Hermes: UK late payments hit two-year high at 2015 year-end.

Griffiths, R., Wayne, L. \& Jeremy, C. (2017). Projects bank accounts: the second wave of security of payment? Journal of Financial Management of Property and Construction, 22(3).

Kilgallon, B. (2013). The Late Show: Project Bank Accounts. RICS Construction Journal, pp. 14-17.

Pay safe: Lost in Transaction Payment Trends (2018). Available from: Retrieved from https:// www.paysafe.com/fileadmin/content/pdf/Lost_in_Transaction_2018_-_Paysafe_-_web_ spreads.pdf.

Peter \& Arewa (2018). Potentiality of Emerging Technologies to Minimise Late-Payments Quandary in Construction. In: Gorse and Neilson, C, J (Eds) Proceedings of the 34th Annual ACROM Conference, 3-5 September, 2018, Association of Researchers in Construction Management, pp. 47-56, Belfast, the UK.

Ramachandra, T. \& Rotimi, J. O. B. (2015). Causes of Payment Problems in the New Zealand Construction Industry. Construction Economics and Building, 15(1), pp. 43-55.

The UK Cabinet Office (2013-14) Sixth Report of Session: Improving government procurement and the impact of government's ICT savings initiatives. Ordered by the House of Commons Committee of Public Accounts.

Zurich Index (2017) SMEs owed more than $£ 44.5$ bn in late payments. Retrieved from https:// www.zurich.co.uk/en/about-us/media-centre/general-insurance-news/2017/smes-owedmore-than-45bn-in-late-payments [Retrieved on 21July 2019]. 